\title{
Postnatal Development of Phase-Locked High-Fidelity Synaptic Transmission in the Medial Nucleus of the Trapezoid Body of the Rat
}

\author{
Nao Chuhma and Harunori Ohmori \\ Department of Physiology, Faculty of Medicine, Kyoto University, Kyoto 606-01, Japan
}

Synaptic transmission in the medial nucleus of the trapezoid body of rats was analyzed in postnatal days 4-13 (P4-P13) by applying the whole-cell patch-recording technique to brain slices. In P4-P6 animals, evoked EPSCs fluctuated extensively in amplitude and occurred in marked asynchrony, followed by spontaneous EPSCs. With development of animals, the evoked EPSCs increased in amplitude, and the rise time became faster. In addition, the synaptic transmission became phase-locked. The coefficient of variation (CV) of EPSC amplitude decreased with development $(0.32 \pm 0.03$ for P4-P5 and $0.05 \pm 0.01$ for P9-P11). The amplitude of miniature EPSCs did not change throughout the postnatal days investigated $(-30.2 \pm 0.3 \mathrm{pA}$ at
$-70 \mathrm{mV})$. The CV was dependent on extracellular $\mathrm{Ca}^{2+}$ concentration $\left(\left[\mathrm{Ca}^{2+}\right]_{0}\right)$ and was reduced with the increase of $\left[\mathrm{Ca}^{2+}\right]_{0}$, and this $\left[\mathrm{Ca}^{2+}\right]_{0}$ dependence was shifted toward lower $\left[\mathrm{Ca}^{2+}\right]_{0}$ with development. Direct patch recording of the presynaptic terminals demonstrated an increase in $\mathrm{Ca}^{2+}$ currents during these postnatal days. The phase-locked highfidelity transmission in this synapse is achieved with development likely through the increase of $\mathrm{Ca}^{2+}$ currents and $\mathrm{Ca}^{2+}$ sensitivity of transmitter release mechanisms in the presynaptic terminal.

Key words: MNTB; development; synapse; EPSC; coefficient of variation; presynaptic $\mathrm{Ca}^{2+}$ currents; calyx of Held
The medial nucleus of the trapezoid body (MNTB) is a relay nucleus in the auditory system. The principal neuron of MNTB receives a glutamatergic input from a globular bushy cell in the contralateral anteroventral cochlear nucleus (AVCN) (Wu and Kelly, 1992; Suneja et al., 1995) and sends an inhibitory projection fiber to neurons in the ipsilateral lateral superior olive (LSO) nucleus (Morest, 1968). The MNTB likely contributes to the binaural sound localization, and the synapse formed onto it has a large calyx-shaped presynaptic terminal (calyx of Held) (Held, 1893). In mature animals the synapse is characterized by the phase-locked, highly reliable (high-fidelity) transmission (Goldberg and Brown, 1968; Aitkin 1986; for review, see Koyano and Ohmori, 1996).

The presynaptic terminal in MNTB was identified morphologically at the day of birth [postnatal day $0(\mathrm{P} 0)$ ] as thin, filamentous terminal processes around the principal neuron. During postnatal development terminal swellings with radiating filopodia-like processes emerged at around P5, followed by their extensive transformation into digit-like structures surrounding the principal neuron. The mature calyx of Held was observed at around P14-P16 (Kandler and Friauf, 1993; Kil et al., 1995). Because both the presynaptic terminal and postsynaptic neuron are electrophysiologically accessible, the properties of both presynaptic terminals and postsynaptic responses have been investigated extensively (Barnes-Davies and Forsythe, 1995; Borst et al., 1995; Takahashi et al., 1996). However, the development of synaptic transmission

Received Aug. 21, 1997; revised Oct. 14, 1997; accepted Oct 17, 1997.

This work was supported by grants-in-aid from the Ministry of Education. N.C. is a research fellow of the Japan Society for the Promotion of Sciences. We acknowledge Dr. M. E. Barish for valuable comments and contributions to improving this manuscript and Dr. T. Hirano, Dr. Y. Kang, and Dr. K. Koyano for reading this manuscript. Dr. M. Takada is appreciated for helpful discussions and suggestions. We also thank Mr. M. Fukao for excellent technical assistance.

Correspondence should be addressed to Harunori Ohmori at the above address.

Copyright (C) 1997 Society for Neuroscience $0270-6474 / 97 / 180512-09 \$ 05.00 / 0$ has not been investigated previously, and the underlying mechanisms leading to the phase-locked high-fidelity nature of this synaptic transmission remain unclear.

We have applied the whole-cell patch-recording technique to this synapse in P4-P13 rats and have investigated the development of synaptic transmission. The extremely reliable, phaselocked synaptic transmission was established during early postnatal development and accompanied an increase in presynaptic $\mathrm{Ca}^{2+}$ currents and an increase in $\mathrm{Ca}^{2+}$ sensitivity of synaptic transmission.

\section{MATERIALS AND METHODS}

Preparation of brain slices. Wistar rats aged P4-P13 were deeply anesthetized with ether. After decapitation, the brainstem was removed together with the cerebellum. This block of brain was cooled in ice-cold $35 \mathrm{~mm}$ glucose saline (35GS; in mu: $130 \mathrm{NaCl}, 4.5 \mathrm{KCl}, 2 \mathrm{CaCl}_{2}, 5$ PIPES-Na, and 35 glucose, $\mathrm{pH}$ 7.4) saturated with $100 \% \mathrm{O}_{2}$ and then mounted in a $3 \%$ agarose gel (Low Gelling Temperature; Nakalai, Kyoto, Japan) prepared with the 35GS. Transverse brain slices (150-300 $\mu \mathrm{m}$ sections) containing MNTB were cut with a vibratome (DTK-2000; Dosaka, Kyoto, Japan). Slices were preincubated in $\mathrm{Ca}^{2+}$-free, high- $\mathrm{Mg}^{2+}$ artificial CSF (Mg-ACSF; in mM: $125 \mathrm{NaCl}, 2.5 \mathrm{KCl}, 26 \mathrm{NaHCO}_{3}, 1.25$ $\mathrm{NaH}_{2} \mathrm{PO}_{4}, 5 \mathrm{MgCl}_{2}$, and 35 glucose, $\mathrm{pH}$ 7.4) saturated with $95 \% \mathrm{O}_{2}-5 \%$ $\mathrm{CO}_{2}$ at $35^{\circ} \mathrm{C}$ for at least $1 \mathrm{hr}$. After preincubation, slices were maintained in a $100 \mathrm{~mm}$ glucose ACSF (100-glucose ASCF; in mM: $75 \mathrm{NaCl}, 2.5 \mathrm{KCl}$, $26 \mathrm{NaHCO}_{3}, 1.25 \mathrm{NaH}_{2} \mathrm{PO}_{4}, 2 \mathrm{CaCl}_{2}, 1 \mathrm{MgCl}_{2}$, and 100 glucose, $\mathrm{pH}$ 7.4) saturated with $95 \% \mathrm{O}_{2}-5 \% \mathrm{CO}_{2}$ at room temperature $\left(20-25^{\circ} \mathrm{C}\right)$. Before recording, the slices were treated with dispase II $(3.3 \mathrm{mg} / \mathrm{ml}$; Boehringer Mannheim, Mannheim, Germany) or DNase I $(0.1 \mathrm{mg} / \mathrm{ml}$; Sigma, St. Louis, MO) in 100-glucose ACSF for 10-15 min at room temperature. This enzyme treatment facilitated formation of gigaohm seals. We did not observe any differences in membrane excitability, including peak amplitude or time course of EPSCs, after enzyme treatment.

Recordings of EPSC and EPSP. A slice was mounted in the recording chamber on the stage of an upright fluorescence microscope equipped with Nomarski optics (BX50WI; Olympus, Tokyo, Japan). The chamber was continuously circulated with standard ACSF (in mM: $125 \mathrm{NaCl}, 2.5$ $\mathrm{KCl}, 26 \mathrm{NaHCO}_{3}, 1.25 \mathrm{NaH}_{2} \mathrm{PO}_{4}, 2 \mathrm{CaCl}_{2}, 1 \mathrm{MgCl}_{2}$, and 17 glucose, 
$\mathrm{pH}$ 7.4). The MNTB neurons were monitored through a CCD camera (C2400-07ER; Hamamatsu Photonics, Hamamatsu, Japan) and were contrast-enhanced using an image processor (Argus-10; Hamamatsu Photonics). Whole-cell recordings were made with an Axopatch 200A amplifier (Axon Instruments, Foster City, CA) or with an EPC-7 amplifier (List). Patch pipettes were fabricated from thin-walled borocilicate glass capillaries and were coated with Sylgard (Dow Corning Asia). Pipette resistances were $\sim 3-5 \mathrm{M} \Omega$. The composition of pipette solution was as follows (in mM): $140 \mathrm{~K}$-gluconate, $11 \mathrm{KCl}, 0.5$ EGTA, $10 \mathrm{HEPES}$ and $5.5 \mathrm{KOH}, \mathrm{pH}$ 7.3. To block $\mathrm{Na}^{+}$currents, a local anesthetic, QX314 (5 mm; Alamone labs, Jerusalem, Israel), was added to the pipette solution. The liquid junction potential (approximately $-10 \mathrm{mV}$ ) was corrected. Neurons were voltage-clamped at $-70 \mathrm{mV}$. Presynaptic nerve fibers were electrically stimulated by a bipolar tungsten electrode placed on the trapezoid body halfway between the midline and the MNTB. A single pulse (3-21 V, $100 \mu \mathrm{sec}$ duration) was applied every $5 \mathrm{sec}$. The stimulus voltage required to induce postsynaptic responses was higher in $\mathrm{P} 4-\mathrm{P} 5$ preparations $(>15 \mathrm{~V})$ than in more mature preparations $(3-8 \mathrm{~V})$. The approximate distance between the location of the stimulating electrode and the medial edge of MNTB was $200 \mu \mathrm{m}$ in P4 and $240 \mu \mathrm{m}$ in P12 preparations. The medial to lateral diameter of MNTB was $430 \mu \mathrm{m}$ at $\mathrm{P} 4$ and $660 \mu \mathrm{m}$ at $\mathrm{P} 12$. Because of its winding projection, the exact length of the afferent fiber between the stimulus electrode and the calyx could not be determined accurately. All experiments were performed at room temperature $\left(20-25^{\circ} \mathrm{C}\right)$.

MNTB neurons are reported to receive both glycinergic and glutamatergic inputs, and both NMDA and non-NMDA receptors are expressed at the early postnatal days (Forsythe and Barnes-Davies, 1993). The glycinergic input was blocked by adding $20 \mu \mathrm{M}$ strychnine (Sigma); NMDA receptors were blocked by $50 \mu \mathrm{M}$ D-2-amino-5phosphonovalerate (APV; Tocris).

We have accepted the recorded EPSCs only when the following two conditions were satisfied. (1) The evoked EPSC showed all-or-none responses to changes in stimulus intensity. This criterion was to ensure that the EPSC was generated from a single presynaptic terminal. There was no change in this all-or-none response property of evoked EPSC during the period P4-P11. (2) The evoked EPSC had the maximum peak amplitude $>300 \mathrm{pA}$ at $-70 \mathrm{mV}$. This criterion was to maintain a sufficient signal-to-noise ratio. Series resistance was 24-36 $\mathrm{M} \Omega$ and was compensated by $40-70 \%$ in most experiments. The extent of series resistance compensation affected the amplitude and time course of EPSCs. In a few experiments, especially in younger animals, series resistance compensation was not made, because of the extra noise induced. Series resistance was compensated by $>70 \%$ in all experiments in which the rise time of EPSCs was measured. The presence of series resistance compensation did not affect the extent of fluctuation of the peak amplitude of EPSCs $(n=4$ cells; paired $t$ test, $p<0.005)$.

Voltage commands were generated by a programmable stimulator (OI-8; Shosin EM, Okazaki, Japan). Data were low-pass-filtered at $5 \mathrm{kHz}$ with four-pole Bessel characteristics, analog-to-digital (A/D) sampled at $40-500 \mu \mathrm{sec}$ intervals with 12 bit resolution, and stored in a personal computer (PC-9801 FA; NEC, Tokyo, Japan).

Recording of presynaptic $\mathrm{Ca}^{2+}$ current and action potentials. Whole-cell recordings from the calyces of Held were made by a patch pipette with electrode resistance of 5-10 $\mathrm{M} \Omega$ (see Fig. 1A). The pipette solution contained (in mM): 136 Cs-glucuronate, $14 \mathrm{CsCl}, 10 \mathrm{HEPES}-\mathrm{Cs}, 5$ EGTA, $5 \mathrm{Mg}$-ATP, and 5 creatine phosphate, and $\mathrm{pH}$ was adjusted to 7.3. Lucifer yellow $(1 \mathrm{mg} / \mathrm{ml})$ was added to the pipette solution, and the recording from calyx terminal was confirmed by fluorescence imaging at the end of each experiment. Presynaptic $\mathrm{Ca}^{2+}$ currents were recorded in either $2 \mathrm{mM} \mathrm{CaCl}_{2}, 1 \mathrm{~mm} \mathrm{MgCl}_{2}$ or $0.75 \mathrm{~mm} \mathrm{CaCl}_{2}, 2 \mathrm{~mm} \mathrm{MgCl} \mathrm{M}_{2}$ medium. Both contained $1 \mu \mathrm{M}$ TTX to block $\mathrm{Na}^{+}$currents and $1 \mathrm{mM}$ 4-aminopyridine and $20 \mathrm{~mm}$ tetraethylammonium chloride by replacing equimolar $\mathrm{NaCl}$ in the standard ACSF to block $\mathrm{K}^{+}$currents. $\mathrm{Ca}^{2+}$ currents were recorded in response to step pulses of $20-100 \mathrm{msec}$ duration applied at $5 \mathrm{sec}$ intervals to voltages between -100 and $+40 \mathrm{mV}$ from the holding potential of $-80 \mathrm{mV}$. Rundown of $\mathrm{Ca}^{2+}$ currents was accelerated by an increased rate of repetition of step depolarizations. Series resistance was $12-35 \mathrm{M} \Omega$ and was compensated by $70-85 \%$. Data were low-pass-filtered at $5 \mathrm{kHz}$ with four-pole Bessel characteristics and were A/D sampled at 100-300 $\mu \mathrm{sec}$. In some recordings, a pulse-dividedby-four protocol was used to subtract leakage currents. However, most recordings were made from presynaptic terminals of minimum leakage conductance without leak subtraction.

In experiments involving recording from both presynaptic terminals and postsynaptic neurons, the presynaptic terminal was current-clamped, and action potentials were generated by current injection through a recording patch electrode. The patch electrode was filled with a $\mathrm{K}^{+}$based internal medium: $120 \mathrm{~K}^{+}$-glucuronate-based medium for tip filling and $120 \mathrm{~K}^{+}$-glutamate-based medium for the back fill. Both solutions further contained (in mM): $20 \mathrm{KCl}, 0.2 \mathrm{EGTA}, 5 \mathrm{Mg}$-ATP, and 5 creatine phosphate and were adjusted to $\mathrm{pH} 7.4$ by $10 \mathrm{~mm}$ HEPES-K ${ }^{+}$. Without back filling with $\mathrm{K}^{+}$-glutamate, we could not induce EPSCs in the postsynaptic neuron. The postsynaptic neuron was voltage-clamped as described above.

Data analysis. All data were analyzed by commercially available software (Axograph; Axon Instruments). Rise time of the EPSCs was defined as the time between 20 and $80 \%$ of the peak amplitude. The amplitude fluctuation of EPSCs was analyzed from $>50$ consecutively recorded traces. Statistical calculations were made in subgroups of 10 consecutive EPSC records to eliminate additional variation from the trend. Then a grand average was made and used as the statistic of an individual experiment. The statistical nature of the amplitude fluctuation of EPSCs was analyzed in two ways: as the coefficient of variation $(\mathrm{CV})$ and as the ratio of variance to mean $\left(\sigma^{2} / \mu\right)$. The CV is defined as the ratio of the $\mathrm{SD}$ to the mean. If we assume binomial statistics, both $\mathrm{CV}$ and $\sigma^{2} / \mu$ will be expressed as follows:

$$
\begin{gathered}
\mathrm{CV}=\sqrt{\frac{1}{N}\left(\frac{1}{p}-1\right)}, \\
\frac{\sigma^{2}}{\mu}=q(1-p),
\end{gathered}
$$

where $N$ is the number of transmitter release sites in a presynaptic terminal, $p$ is the release probability, and $q$ is the mean miniature EPSC (mEPSC) amplitude. The binomial statistic assumes that (1) $p$ is constant in response to each electrical stimulation and among release sites, and (2) $q$ is constant. These assumptions will be discussed later.

mEPSCs were observed in young animals (P4-P7), particularly after evoked EPSCs, and sizes of these mEPSCs were measured. To avoid contamination with evoked EPSCs of small size, mEPSCs were measured only from the late phase of the traces, which had apparent preceding evoked EPSCs. In animals older than P9, mEPSCs were induced by adding $10 \mathrm{mM} \mathrm{BaCl}_{2}$ and $1 \mu \mathrm{M}$ TTX to the external solution together with APV $(50 \mu \mathrm{M})$, strychnine $(20 \mu \mathrm{M})$, and bicuculline $(20 \mu \mathrm{M})$. In these older animals, mEPSCs were rarely observed even after evoked EPSCs.

The mean amplitude of mEPSCs $(q)$ was calculated by averaging the amplitudes of recorded mEPSCs from groups of events that had a single peak in the amplitude histogram. Most of the amplitude histograms of mEPSCs had a single peak, and the distribution was slightly skewed toward larger amplitudes (see Fig. $8 B$ ). Some of the amplitude histograms of $\mathrm{Ba}^{2+}$-induced mEPSCs had more than two peaks and were not included in this calculation to avoid contamination of multiquantal events.

Data are given as mean \pm SE (number of cells), unless otherwise noted.

\section{RESULTS}

\section{Formation of the calyx of Held}

The formation of calyces of Held is initiated by terminal swelling at around P5, and the adult-like morphology is seen by P14 in rat (Kandler and Friauf, 1993). We have confirmed the morphological development of the synapse by injection of Lucifer yellow into the presynaptic terminal through the patch electrode (Fig. $1 B, C)$. On P5, the presynaptic terminal did not encircle the postsynaptic neuron but showed marked swellings and had many filopodia-like structures (Fig. $1 B$ ). The presynaptic terminal became thicker with maturation and covered the large surface area of the postsynaptic neuron by $\mathrm{P} 10$, exhibiting the shape of a mature calyx (Fig. $1 A, C$ ).

\section{Achievement of high-fidelity synaptic transmission}

We recorded evoked EPSPs and action potentials from MNTB neurons at P4-P11 (Fig. 2). When the projection fiber from AVCN was electrically stimulated, the principal neuron of 

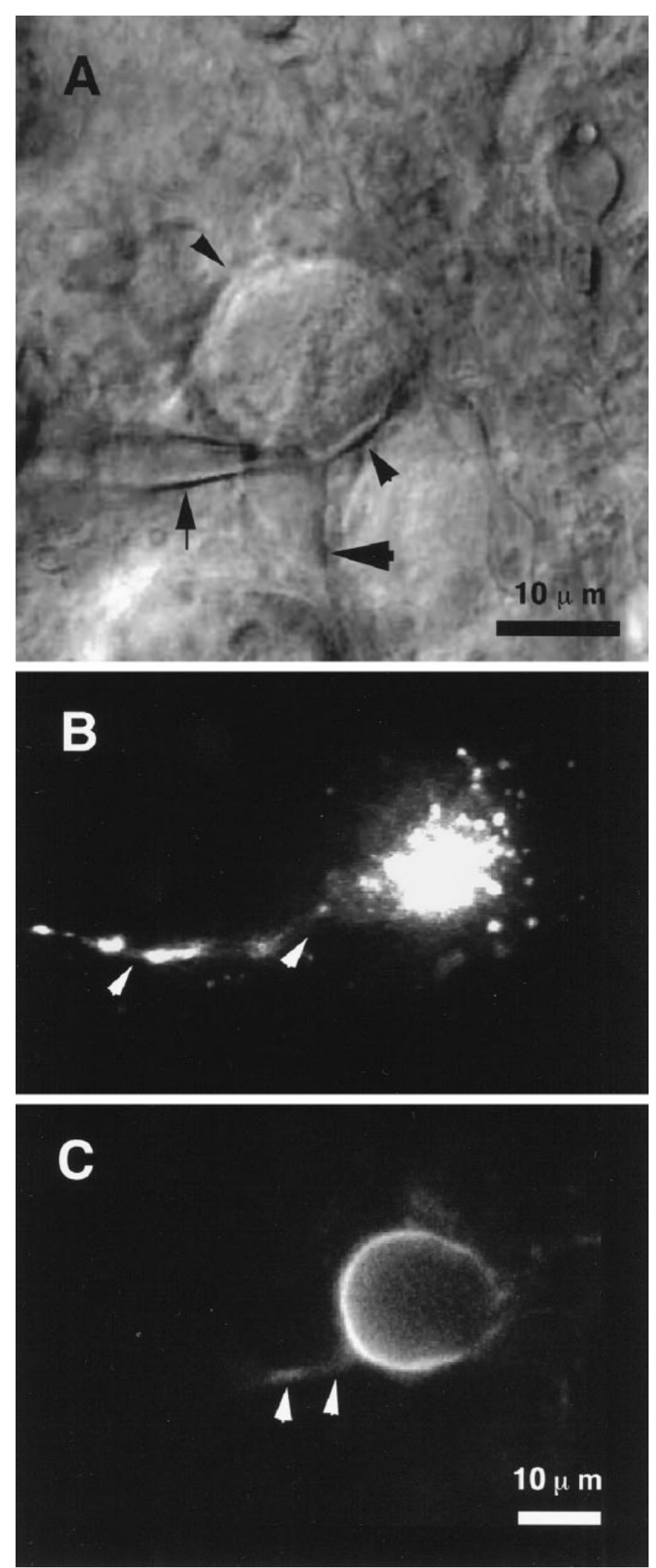

Figure 1. Nomarski and fluorescence images of calyces of Held. $A$, Nomarski image of the calyx in a P10 preparation. The calyx (small arrowheads) and the presynaptic fiber (large arrowhead) are shown. An arrow indicates a patch electrode. $B, C$, Fluorescence images of calyces. Calyces were stained with Lucifer yellow injected through the patch pipette. $B$, A calyx in a P5 preparation. Arrowheads indicate the presynaptic fiber in $B$ and $C$. $C$, A calyx in a P10 preparation.
A

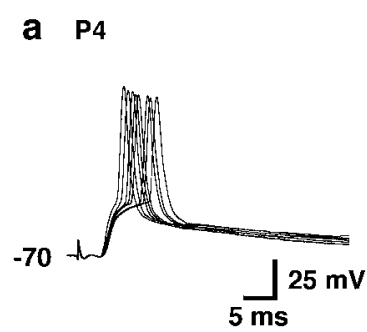

B
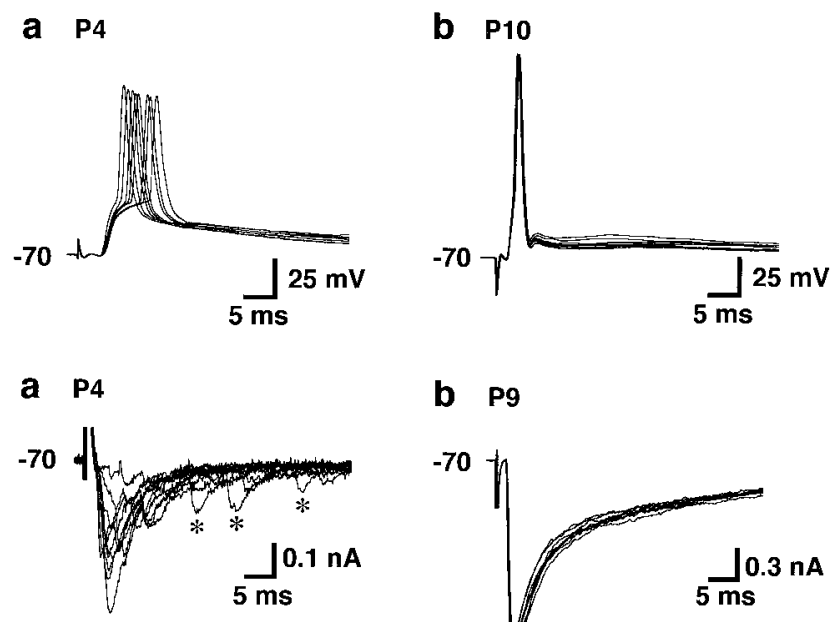

b P9

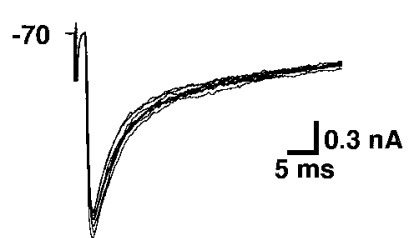

C

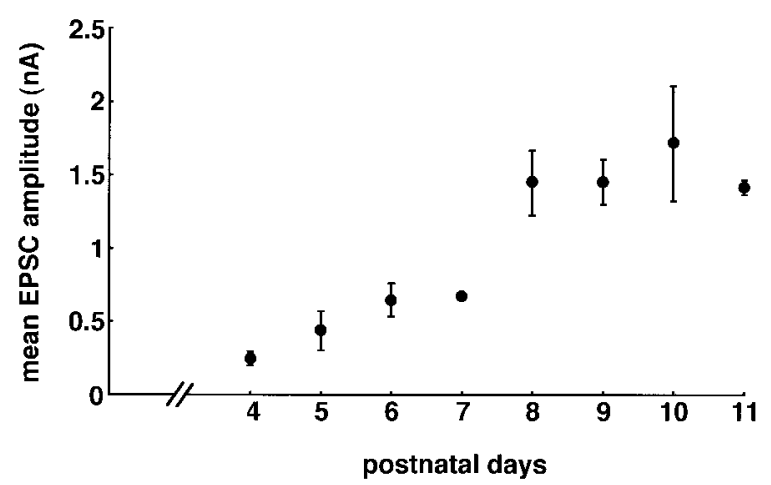

Figure 2. Postnatal development of synaptic transmission. EPSPs and EPSCs were recorded from postsynaptic MNTB neurons with patch electrodes. APV was not added to the external solution in this experiment. $A$, EPSPs and action potentials in $\mathrm{P} 4$ and P10 neurons. Membrane potential was maintained at $-70 \mathrm{mV}$ in both neurons by injecting small currents through the patch pipette. $a$, EPSPs and action potentials from a P4 neuron (8 records were superimposed); $b$, from a P10 neuron (10 records were superimposed). Note a marked contrast in action potential generation from evoked EPSPs between P4 and P10. B, EPSCs in P4 and P9 neurons. The membrane was voltage-clamped at $-70 \mathrm{mV}$. $a$, EPSCs in $\mathrm{P} 4$ neuron. Ten traces were superimposed. Note small mEPSC-like current responses $\left(^{*}\right)$ in late portion of traces. $b$, EPSCs in $\mathrm{P} 9$ neuron. Ten traces were superimposed. $C$, Postnatal changes in the amplitude of evoked EPSCs. Each point was calculated from more than four cells. The large SE at P10 was attributable to a single cell among six cells with exceptionally large EPSC of $3.5 \mathrm{nA}$.

MNTB generated action potentials from EPSPs under currentclamp conditions. On P4, the EPSP rose slowly and generated a single action potential. The timing of action potential generation fluctuated over $5 \mathrm{msec}$ (Fig. $2 A a$ ). With postnatal development, the timing of action potential generation showed less fluctuation. By P10, action potentials fired at almost a fixed interval after electrical stimulation (Fig. 2Ab).

The principal neuron of MNTB is an interneuron in the pathway to the LSO and needs phase-locked transmission to discriminate small time differences between binaural inputs $(\mathrm{Wu}$ and Kelly, 1991; Banks and Smith, 1992). Therefore, the neuron should generate action potentials with minimum timing fluctuations after receiving synaptic input. Figure $2 A$ shows that this feature of action potential generation is completed during the early postnatal days of development. The phase-locked nature of 
MNTB action potential generation could be achieved by several factors, including increased excitability of both the presynaptic terminal and the postsynaptic neuron and changes in synaptic transmission onto the MNTB neuron. Developmental changes in synaptic transmission are also suggested by the extensive morphological transformation of the presynaptic terminal (Fig. 1).

EPSCs were compared at P4 and P9 under voltage-clamp conditions in Figure $2 B$. The sizes of evoked EPSCs at P4 were small, and EPSCs showed extensive fluctuations both in amplitude and in timing (Fig. 2Ba). After the induction of the main EPSCs, small mEPSC-like current transients (*) were frequently observed during P4-P7. Because these mEPSC-like current transients were not observed preceding the evoked EPSCs, these current transients could be an asynchronous part of the evoked synaptic responses. We will refer to these events as mEPSCs hereafter. At P9 EPSCs were larger in amplitude and showed less timing fluctuation (Fig. 2 $\mathrm{Bb}$ ). Mean amplitudes of evoked EPSCs were calculated by measuring the peak of each trace, and averages are plotted against postnatal day in Figure $2 C$. The mean amplitude of evoked EPSCs became larger with development and reached a plateau level about P8. The increase of mean evoked EPSC amplitude (Fig. 2C), together with the reduction of both the amplitude fluctuation and the peak time fluctuation (Fig. 2B), seems essential to development of high-fidelity synaptic transmission at this synapse (Fig. $2 A$ ).

\section{Synchronization of EPSCs with development}

The time course of EPSC rise and decay was accelerated with development. When P4 evoked EPSCs were ensemble-averaged by aligning the stimulus artifact, both the rise time and the total time course were much slower than those of P9 evoked EPSC (Fig. $3 B a, B d, C a$ ). The rise time of evoked EPSCs was $\sim 1 \mathrm{msec}$ (0.96 $\pm 0.03 \mathrm{msec} ; 12$ cells) at P4-P5 and $0.37 \pm 0.01 \mathrm{msec}$ at P9-P11 (seven cells). The falling phase of a P4 EPSC was also slower than that of a P9 EPSC. There is extensive fluctuation in the timing of evoked individual EPSCs in P4 (Fig. $3 A a$ ), whereas the timing was fixed in P9 (Fig. 3Ab).

When P4 evoked EPSCs were ensemble-averaged by aligning the time of $50 \%$ peak amplitude (Fig. $3 B b, B e$ ), the rising phase was almost superimposing on the rising phase of P9 evoked EPSCs (Fig. 3Cb). The falling phase was still delayed to the falling phase of P9 evoked EPSC.

When mEPSCs were extracted from the traces in Figure $3 \mathrm{Aa}$ (Fig. $3 B c$ ) and were ensemble-averaged by aligning the time to reach $50 \%$ of the peak amplitude (Fig. $3 B f$ ), the time course of this ensemble-averaged mEPSC was almost completely superimposing after amplitude scaling on the time course of the P9 evoked EPSC (Fig. 3Cc). Similar results were obtained in three other P4 evoked EPSCs and mEPSCs. The slow rise and fall of averaged P4 evoked EPSCs are thus likely attributable to the asynchronous release of transmitter quanta after electrical stimulation of the presynaptic fiber. The postnatal development of synaptic transmission, therefore, includes both the synchronization of neurotransmitter release (Fig. 3) and the increase in the quantity of neurotransmitter released (Fig. 2C).

\section{Timing fluctuations of evoked EPSCs could be attributable to the timing fluctuations of presynaptic invasion of action potentials}

The timing fluctuation of EPSC onset during early postnatal days might reflect fluctuation of action potential invasion into the presynaptic terminal after electrical stimulation. Figure $4 A$ illus-
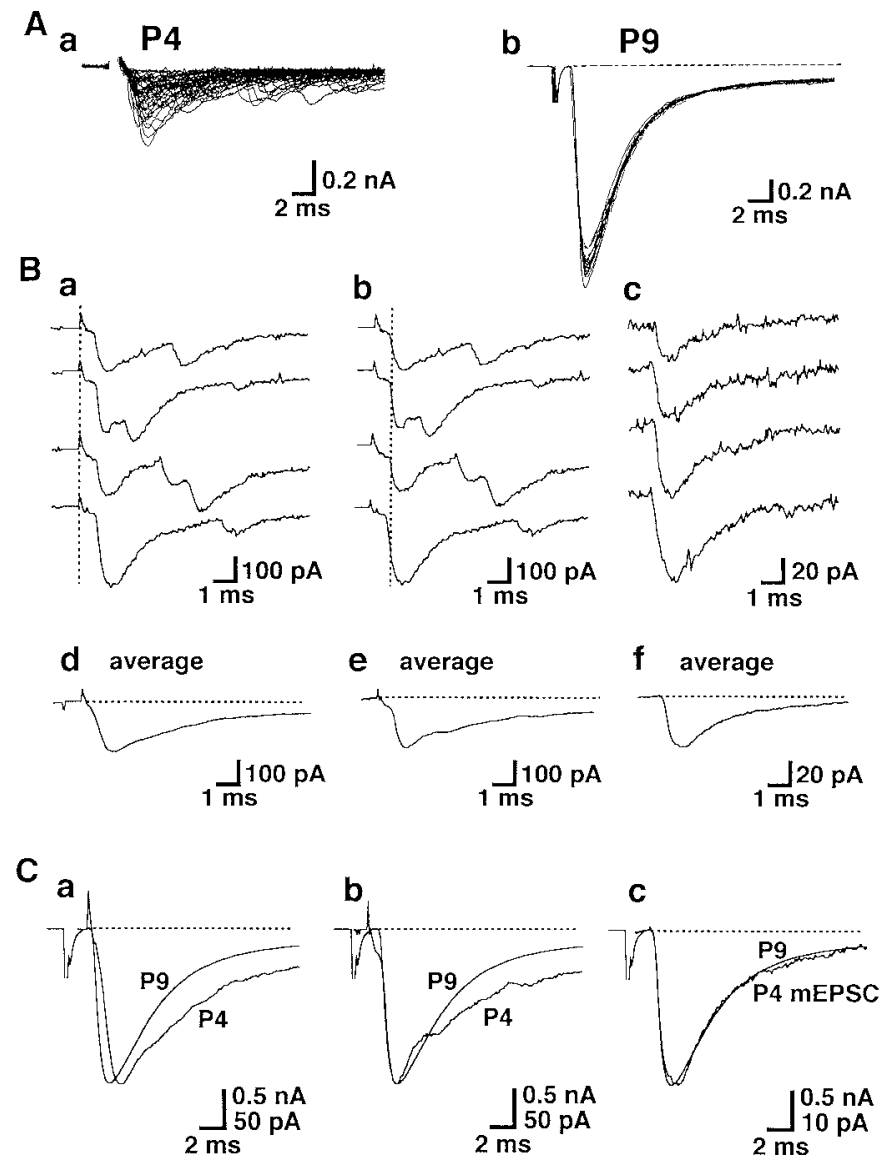

Figure 3. Comparison of the time course of EPSCs between P4 and P9. $A$, Evoked EPSCs were superimposed for P4 ( $a, 69$ traces), and P9 ( $b, 45$ traces) neurons recorded at $-70 \mathrm{mV}$. Note the marked fluctuation in EPSCs in timing and in amplitude at P4 and less fluctuation at P9. The stimulus artifact was retouched in all traces. $B$, Evoked EPSCs and mEPSCs were extracted and rearranged by alignment with the stimulus artifact $(a)$, with the time to reach $50 \%$ of the peak $(b)$ for evoked EPSCs, and for mEPSCs $(c)$. Traces in $a$ and $b$ are the same set of records but time-shifted in $b$. Ensemble averages of traces including four traces shown in $a-c$ are illustrated in $d$ (average of 24 traces), $e$ ( 24 traces), and $f$ (20 traces). $C$, Ensemble averaged traces ( $\mathrm{P} 4)$ in $B, d-f$, are superimposed on the ensemble average of $A, b$ (P9), after amplitude scaling. In $a$, two ensemble-averaged traces are aligned to the stimulus artifact, and the time to reach the $50 \%$ of the peak is shown in $b$ and $c$.

trates several traces from an experiment performed on a P6 synapse in which both presynaptic action potentials and postsynaptic EPSCs were recorded simultaneously. Presynaptic action potentials were generated by current injection. The time of the action potential peak fluctuated over a $3 \mathrm{msec}$ interval, and the time of the EPSC peak showed similar fluctuation. However, when paired records were aligned on the rising phases of action potentials at $50 \%$ of the peak amplitude, the EPSC rising phase was fixed (Fig. $4 B$ ). The time to reach $50 \%$ of action potential peak and that of EPSC peak amplitude were measured from 61 pairs of these traces and are plotted in Figure $4 C$. These two parameters fluctuated over $8.5 \mathrm{msec}$ but showed a significant correlation ( $r=0.99 ; 61$ record pairs). The $x$-intersection of the linear regression line indicates that action potentials preceded EPSCs by $1.04 \mathrm{msec}$. This difference varied from 0.83 to $2.1 \mathrm{msec}$ in six other synapses measured in $\mathrm{P} 6-\mathrm{P} 13$; however, it remained fixed in each synapse ( $r=0.97 \pm 0.04 ; n=6$ cells).

Multiple generation of action potentials in the presynaptic 
A

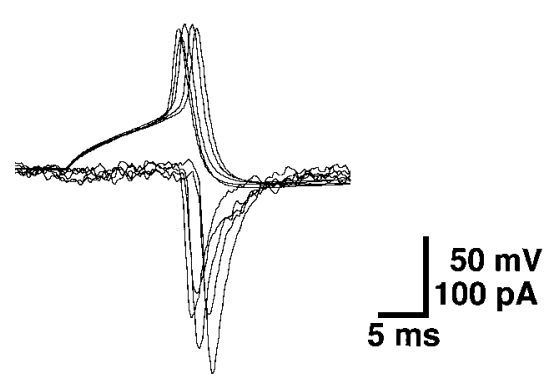

B

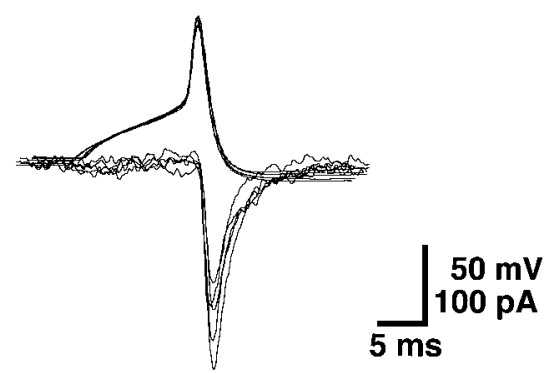

C

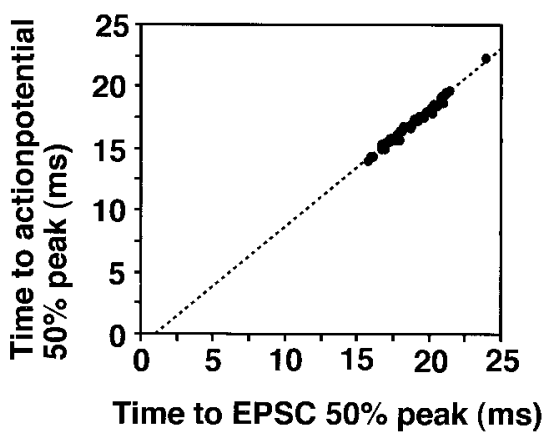

Figure 4. Presynaptic action potentials and EPSCs. $A$, Presynaptic action potentials and EPSCs were simultaneously recorded from a P6 synapse. Consecutively recorded five pairs of traces are superimposed to show fluctuation in onset time. Action potentials were generated by current injection from the resting potential of -72 to $-69 \mathrm{mV}$, and EPSCs were recorded at $-60 \mathrm{mV}$. $B$, Action potentials were aligned to the rising phase (time to reach $50 \%$ of the peak from the resting potential); the paired EPSCs are time-displaced to the same extent. The onset of EPSCs became fixed. $C$, The time to reach $50 \%$ of the action potential peak, and to reach $50 \%$ of the EPSC peak, measured from the onset of current injection to the presynaptic terminal, are plotted. Correlation coefficient was 0.99 . The dotted line is a least square fit to the distribution and was $y=$ $0.96 x-1.007$.

terminal after a single current injection of a short duration was not observed in any of the seven paired recordings and another 21 recordings of preterminal action potentials.

\section{Amplitude fluctuation of EPSCs}

The EPSC amplitude is determined by the number of released transmitter packets and by the corresponding elementary current generated in the postsynaptic membrane (the size of mEPSC) (see Katz, 1966). The number of released packets, or neurotransmitter quanta, is a function of both the number of occupied release sites $(N)$ and the release probability $(p)$. These two presynaptic parameters will determine the $\mathrm{CV}$ of the amplitude fluctuation (see Materials and Methods; Fig. 5, inset) (Korn and Faber, 1991). Figure 5 shows the $\mathrm{CV}$ as a function of postnatal age. On P4, the CV was large ( $0.32 \pm 0.03$, eight cells); it decreased with postnatal development and reached a constant

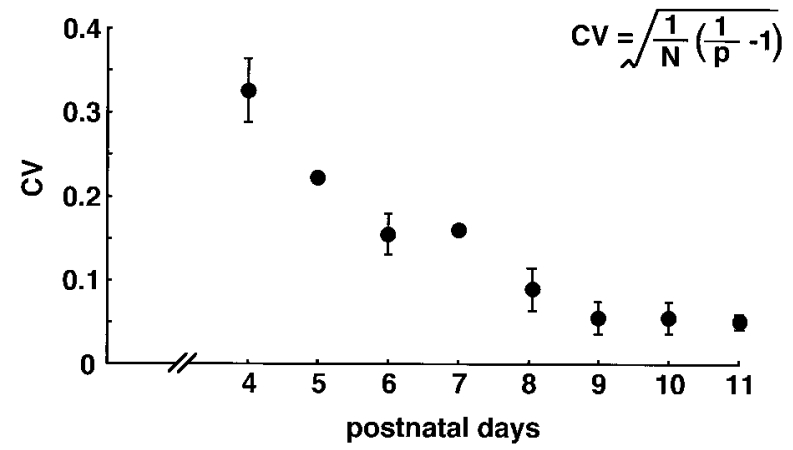

Figure 5. Decrease in the EPSC amplitude fluctuation with postnatal development. CV of EPSC amplitude is plotted against postnatal age. CV was calculated from $>50$ consecutively recorded EPSC traces in each experiment. Each point was calculated from two to eight cells; P5 and P7 were from two cells. Inset, Formulation of $\mathrm{CV}$ in binomial statistics. CV decreased with increasing age, and the decrease was saturated at P9.

value after P9 $(0.05 \pm 0.01,11$ cells of P9-P11). In these evaluations, CVs were calculated from the peak amplitude of EPSCs. When we calculated CVs by time, integrating the entire postsynaptic current induced by a single presynaptic stimulus, these CVs showed a strong correlation with the CVs calculated from the peak amplitudes of EPSCs $(r=0.96 ; 37$ cells from P4-P11) and also decreased with development.

\section{$\mathrm{Ca}^{2+}$ dependence of amplitude fluctuation}

The neurotransmitter release probability or the amplitude of postsynaptic electrical responses is dependent on the extracellular $\mathrm{Ca}^{2+}$ concentration ([Ca $\left.{ }^{2+}\right]_{\mathrm{o}}$ ) (del Castillo and Katz 1954; Dodge and Rahamimoff 1967). Figure $6 A$ shows evoked EPSCs from both $\mathrm{P} 4$ and $\mathrm{P} 9$, recorded in $2 \mathrm{~mm}\left[\mathrm{Ca}^{2+}\right]_{\mathrm{o}}$ (standard ACSF) and $5 \mathrm{~mm}\left[\mathrm{Ca}^{2+}\right]_{\mathrm{o}}$. As shown already in Figure 2, the amplitudes of P4 EPSCs fluctuated extensively in $2 \mathrm{mM}\left[\mathrm{Ca}^{2+}\right]_{\mathrm{o}}$, whereas P9 EPSCs showed less fluctuation (Fig. $6 A a$ ). In $5 \mathrm{~mm}\left[\mathrm{Ca}^{2+}\right]_{\mathrm{o}}$, the amplitude fluctuations of P4 EPSCs became less obvious (Fig. $6 \mathrm{Ab}$, top traces) and was similar to that of P9 EPSCs in $2 \mathrm{~mm}$ $\left[\mathrm{Ca}^{2+}\right]_{\mathrm{o}}$. The amplitude fluctuations of P9 EPSCs were similarly reduced by increase of $\left[\mathrm{Ca}^{2+}\right]_{\mathrm{o}}$, but to a lesser extent than $\mathrm{P} 4$ EPSCs (Fig. 6Ab, bottom traces).

The effects of $\left[\mathrm{Ca}^{2+}\right]_{0}$ on the amplitude fluctuation of EPSCs were investigated systematically in $0.5-10 \mathrm{mM}\left[\mathrm{Ca}^{2+}\right]_{\mathrm{o}}$. CVs of evoked EPSCs were calculated in two groups of animals: an immature group (P4-P6) and a mature group (P9-P11). In the immature group, the $\mathrm{CV}$ decreased extensively by increase of $\left[\mathrm{Ca}^{2+}\right]_{0}$ to between 1 and $5 \mathrm{~mm}$, and the decrease was almost saturated by $5 \mathrm{~mm}$ and higher $\left[\mathrm{Ca}^{2+}\right]_{\mathrm{o}}($ Fig. $6 \mathrm{~B}, \mathbf{O})$. In the mature group, the $\mathrm{CV}$ was decreased between 0.5 and $2 \mathrm{~mm}\left[\mathrm{Ca}^{2+}\right]_{\mathrm{o}}$, and the decrease was saturated at $2 \mathrm{~mm}$ and higher $\left[\mathrm{Ca}^{2+}\right]_{\mathrm{o}}$ (Fig. $6 \mathrm{~B}$, $\bigcirc)$. The dependence of $\mathrm{CV}$ on $\left[\mathrm{Ca}^{2+}\right]_{\mathrm{o}}$ apparently shifted toward lower $\left[\mathrm{Ca}^{2+}\right]_{0}$ with development, and this may indicate increased $\mathrm{Ca}^{2+}$ sensitivity of the transmitter release mechanism in mature presynaptic terminals.

\section{$\mathrm{Ca}^{2+}$ current in the presynaptic terminal}

Several factors may contribute to the observed increase of $\mathrm{Ca}^{2+}$ sensitivity of the CV in the mature synapses, and the quantity of $\mathrm{Ca}^{2+}$ influx into the presynaptic terminal may be the one important factor. Figure $7 A$ shows $\mathrm{Ca}^{2+}$ currents recorded from presynaptic terminals at $\mathrm{P} 6$ and $\mathrm{P} 10$; their $I-V$ relationships are shown in Figure $7 B$ ( for $\mathrm{P} 6-\mathrm{Ca}^{2+}$ currents; $\bigcirc$ for $\left.\mathrm{P} 10\right)$. The maximum amplitude of presynaptic $\mathrm{Ca}^{2+}$ current was observed 
A

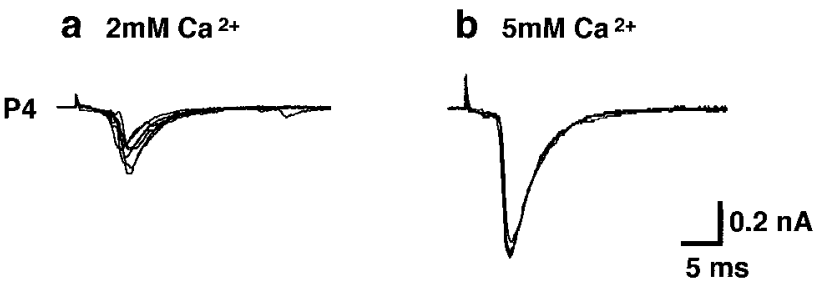

P9
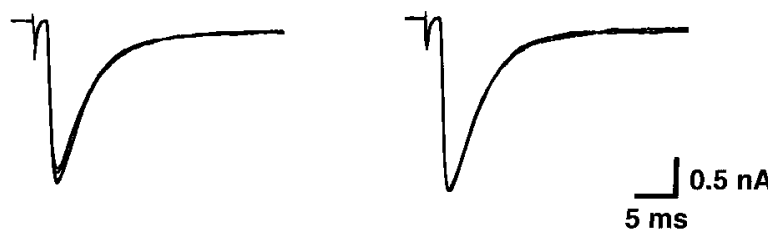

B

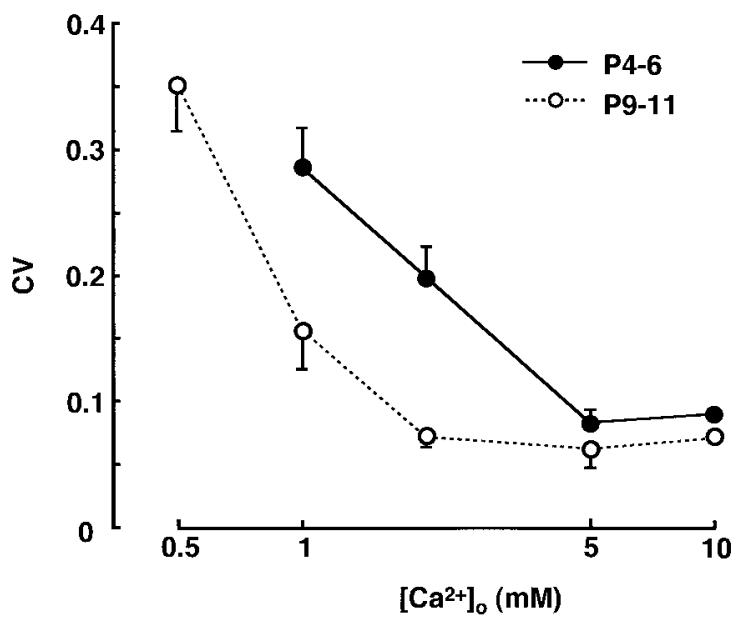

Figure 6. $\quad\left[\mathrm{Ca}^{2+}\right]_{\mathrm{o}}$ dependence of EPSC amplitude fluctuations. $A$, EPSCs recorded in $2 \mathrm{~mm}\left[\mathrm{Ca}^{2+}\right]_{\mathrm{o}}$ (standard ACSF; $a$ ) and in $5 \mathrm{~mm}\left[\mathrm{Ca}^{2+}\right]_{\mathrm{o}}$ $(b)$ in $\mathrm{P} 4$ and $\mathrm{P} 9$ neurons. Four to six traces are superimposed in each panel. $B$, Fluctuation in EPSC amplitude was calculated as CV and was evaluated as a function of $\left[\mathrm{Ca}^{2+}\right]_{\mathrm{o}}$ in two groups of animals, either immature $(\bullet, \mathrm{P} 4-\mathrm{P} 6)$ or mature $(\mathrm{O}, \mathrm{P} 9-\mathrm{P} 11)$. $\mathrm{CV}$ is plotted against $\left[\mathrm{Ca}^{2+}\right]_{0}$ on semilogarithmic coordinates. All points are from measurements of two to nine cells; $10 \mathrm{~mm}\left[\mathrm{Ca}^{2+}\right]_{\mathrm{o}}$ was from two cells.

at -25 to $-10 \mathrm{mV}$ in $2 \mathrm{~mm}\left[\mathrm{Ca}^{2+}\right]_{\mathrm{o}}$, irrespective of animal age $(-20.0 \pm 2.2 \mathrm{mV}$ for P5-P6, six cells; $-17.9 \pm 2.8 \mathrm{mV}$ for P7, seven cells; $-20.8 \pm 3.5 \mathrm{mV}$ for P10-P11, six cells; ANOVA, $p=$ $0.95)$. With the progress of postnatal development, the maximum amplitude of presynaptic $\mathrm{Ca}^{2+}$ currents increased (Fig. $7 \mathrm{C}$ ): $-0.86 \pm 0.06 \mathrm{nA}$ for P5-P6 (six cells), $-1.05 \pm 0.10 \mathrm{nA}$ for P7 (seven cells), and $-1.75 \pm 0.15 \mathrm{nA}$ for P10-P11 (six cells). This increase of presynaptic $\mathrm{Ca}^{2+}$ currents is consistent with the

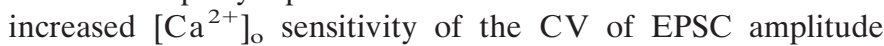
fluctuations with development.

Because the complex morphology of presynaptic terminals may affect the quality of space clamp, the absolute value of $\mathrm{Ca}^{2+}$ currents may be underestimated. However, in recordings with small series resistance and with proper compensation, we should have overcome most problems arising from this complex structure (see Llano et al., 1991). We have tested the validity of the postnatal increase of $\mathrm{Ca}^{2+}$ currents in two ways. (1) When we recorded $\mathrm{Ca}^{2+}$ currents with $\left[\mathrm{Ca}^{2+}\right]_{\text {o }}$ reduced to $0.75 \mathrm{~mm}$ (with
A a
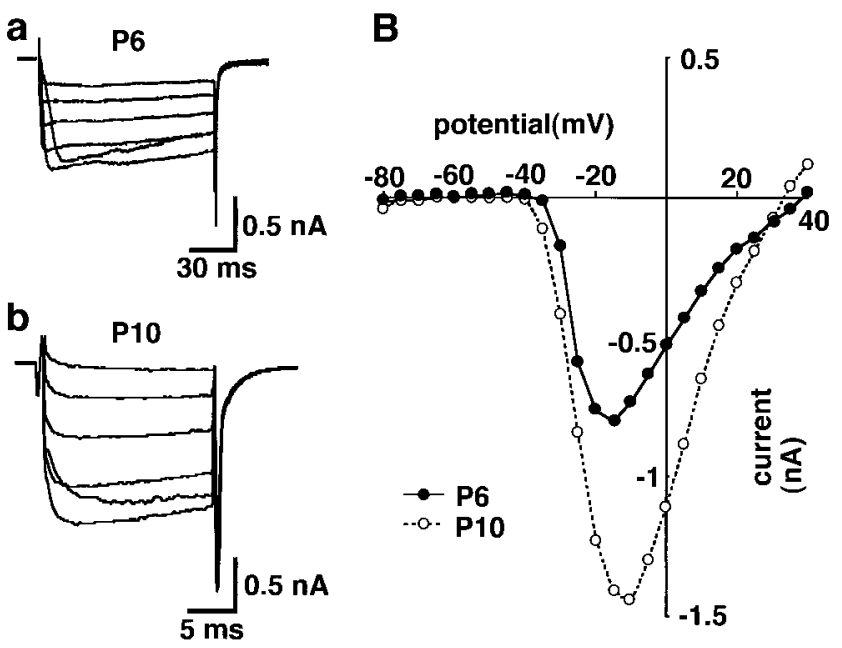

C

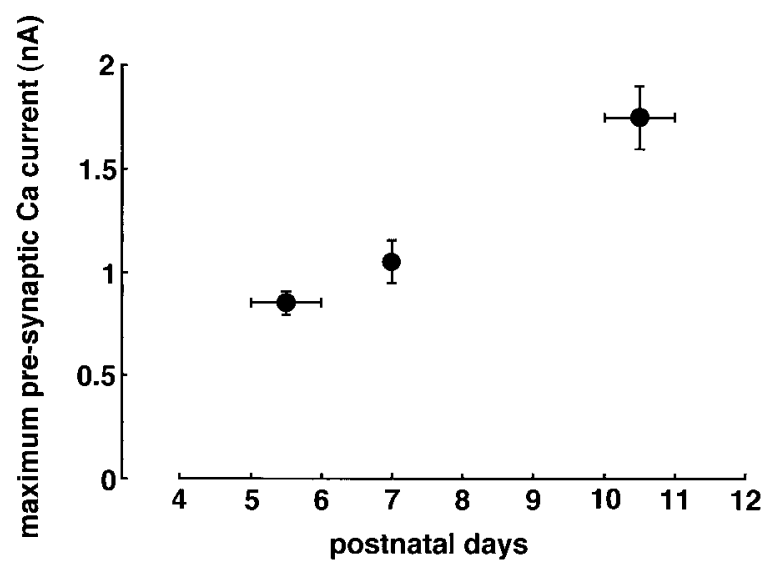

Figure 7. Presynaptic $\mathrm{Ca}^{2+}$ current. $A, a, \mathrm{Ca}^{2+}$ current recorded from a $\mathrm{P} 6$ presynaptic terminal. The holding potential was $-80 \mathrm{mV}$, and $\mathrm{Ca}^{2+}$ current was induced by step depolarizations; traces illustrated were recorded at $-20,-15,-5,5,15$, and $25 \mathrm{mV} . A, b, \mathrm{Ca}^{2+}$ current recorded from a P10 presynaptic terminal. The holding potential was $-80 \mathrm{mV}$, and the traces illustrated were recorded at $-15,-10,0,10,20$, and $30 \mathrm{mV} . B$, $I-V$ relationships of presynaptic $\mathrm{Ca}^{2+}$ currents of a $\mathrm{P} 6$ neuron $(-)$ and a P10 neuron (O). $C$, Mean maximum amplitude of presynaptic $\mathrm{Ca}^{2+}$ current plotted against postnatal age. Animals were placed into three groups: immature (P5-P6), intermediate (P7), and mature (P10-P11). Horizontal bars at each point indicate the range of postnatal days included at that point, and error bars indicate SE. Each point was the average of six or seven cells.

$2 \mathrm{~mm}\left[\mathrm{Mg}^{2+}\right]_{\mathrm{o}}$ ), the mean maximum $\mathrm{Ca}^{2+}$ current amplitude was $-270 \pm 19 \mathrm{pA}$ at P6 (three cells), $-476 \pm 25 \mathrm{pA}$ at P8 (three cells), and $-633 \pm 49 \mathrm{pA}$ at P10-P11 (three cells). These values are close to the expectation from the $\mathrm{Ca}^{2+}$ current averages in Figure $7 C$ and from the ratio of $\left[\mathrm{Ca}^{2+}\right]_{\circ}$ of 0.75 and $2 \mathrm{~mm}$. (2) When series resistance compensation $(70-85 \%)$ was turned off intentionally, the amplitude of maximum $\mathrm{Ca}^{2+}$ current became smaller by $32 \pm 34 \%$ ( 16 cells). The reduction was independent of postnatal age (ANOVA, $p=0.38$ ): $56 \pm 44 \%$ (four cells) from P5-P6, $13 \pm 9 \%$ (five cells) from P7, and $32 \pm 35 \%$ (seven cells) from P10-P11. These reductions of $\mathrm{Ca}^{2+}$ current amplitude partly reflect the rundown of presynaptic $\mathrm{Ca}^{2+}$ channels; the $\mathrm{Ca}^{2+}$ currents obtained with the series resistance compensation tuned to the initial level were still smaller by $16 \pm 20 \%$ (eight cells) than those recorded previously without compensation. De- 
A

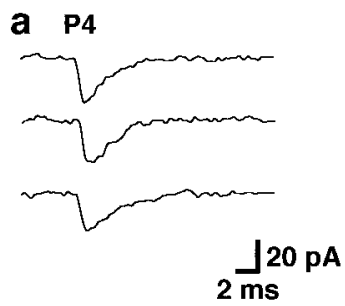

B

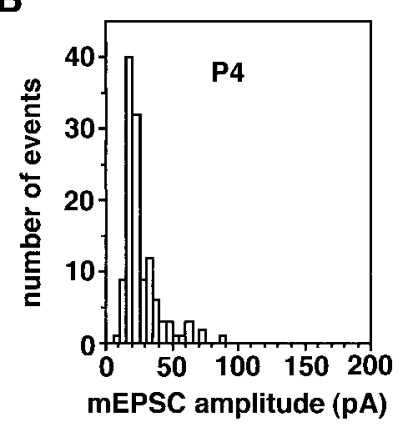

b $\mathbf{P g}$
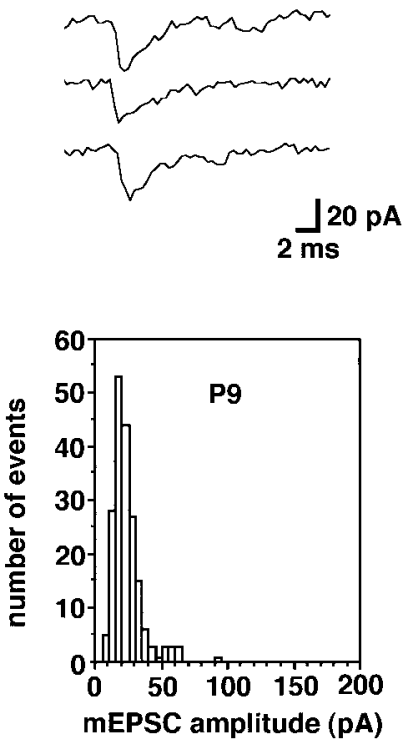

C

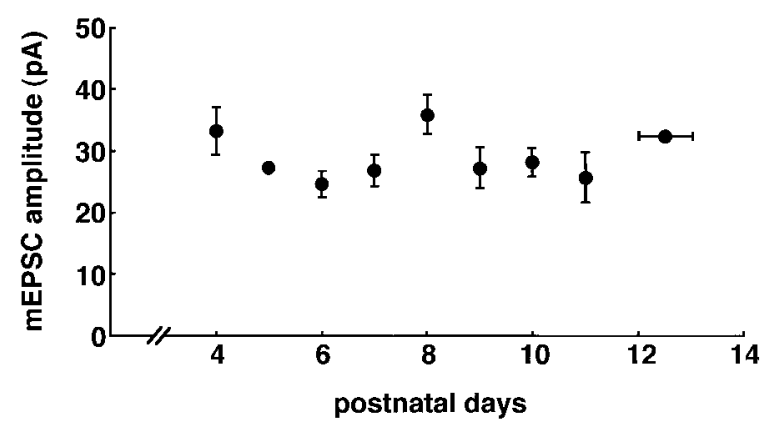

Figure 8. Amplitudes of mEPSCs. A, mEPSCs recorded in P4 ( $a$ ) and P9 (b) neurons. $a$, mEPSCs were extracted from traces after evoked EPSCs. $b$, mEPSCs generated in external solution enriched with $10 \mathrm{mM} \mathrm{Ba}^{2+}$ and $1 \mu \mathrm{M}$ TTX (high $\mathrm{Ba}^{2+}$-ACSF). $B$, Amplitude histograms of absolute value of mEPSCs in a P4 neuron (left) and a P9 neuron (right). The mean mEPSC of the P4 histogram was $-26.5 \mathrm{pA}$ and was $-23.6 \mathrm{pA}$ for the P9 histogram. $C$, Mean absolute amplitudes of mEPSCs plotted against postnatal day. Each point is the average of more than three cells, except for P12 and P13 (1 cell). Mean of P12 and P13 is plotted as a single point with a horizontal bar.

spite the difficulty of obtaining perfect recordings, because of the complex morphology of the presynaptic terminal, these data suggest that the presynaptic $\mathrm{Ca}^{2+}$ currents are increasing during this postnatal period.

\section{Miniature EPSC}

Figure $8 A$ shows traces of spontaneous EPSCs (mEPSCs) recorded at $\mathrm{P} 4$ and $\mathrm{P} 9$. Although mEPSCs were rarely observed in this synapse after maturation, mEPSCs were frequently observed immediately after the evoked EPSCs in P4-P7 neurons (Figs. $2 B a, 3 A a, B)$. Several traces of these mEPSCs are presented in Figure $8 A a$. In older synapses of P8-P13 neurons, mEPSCs were induced by extracellular application of $\mathrm{Ba}^{2+}(10 \mathrm{mM})$ (Fig. $\left.8 A b\right)$. In some neurons at P7-P8, mEPSCs could be recorded both after evoked EPSCs and by extracellular application of $\mathrm{Ba}^{2+}$. The amplitude did not differ significantly between these two sets of mEPSCs $(t$ test, $p=0.50):-29.3 \pm 1.6 \mathrm{pA}$ after evoked EPSCs (17 cells) and $-31.2 \pm 2.4 \mathrm{pA}$ by $\mathrm{Ba}^{2+}$ induction (17 cells).

Amplitude histograms of mEPSCs with a clear single peak are shown in Figure $8 B$ for P4 (left) and P9 (right) neurons. These histograms were constructed from data that included the traces illustrated in Figure $8 \mathrm{~A}$. Most of the mEPSC amplitude histograms had a single peak and showed a distribution skewed toward the larger amplitudes. In a few cases, histograms had several peaks, particularly when mEPSCs were induced by $\mathrm{Ba}^{2+}$ (see Materials and Methods). The mean absolute value of mEPSC $q$ was calculated at each synapse and is plotted against ages of animals in Figure $8 C$; $q$ was almost constant throughout (30.2 \pm $0.3 \mathrm{pA})$. The time constant of mEPSC decay was not significantly changed during P4-P13 (ANOVA, $p=0.38$ ): $2.2 \pm 0.1 \mathrm{msec}$ in P4-P5 ( $n=4$ cells), $2.1 \pm 0.1 \mathrm{msec}$ in P7-P8 $(n=4$ cells $)$, and $2.3 \pm 0.1 \mathrm{msec}$ in $\mathrm{P} 9-\mathrm{P} 13(n=5$ cells $)$.

\section{DISCUSSION}

\section{Achievement of high-fidelity synaptic transmission with development}

We have recorded EPSCs in the large calyx-shaped synapse formed onto the principal neuron of MNTB in animals aged P4-P13 and have investigated developmental changes of synaptic transmission. The amplitude of evoked EPSCs increased with development (Fig. 2C). In younger animals evoked EPSCs fluctuated extensively both in their timing of occurrence and in their amplitude (Fig. 2B) and showed less fluctuation with development (Figs. 2, 3, 5). Development of the characteristic phaselocked, high-fidelity synaptic transmissions was completed at around $\mathrm{P} 9$.

We have evaluated the extent of EPSC amplitude fluctuation by calculating the CV. Postnatal development was accompanied by decrease of the CV and increased $\mathrm{Ca}^{2+}$ sensitivity (Figs. 5, 6). These changes are likely attributable to increase in $\mathrm{Ca}^{2+}$ currents in the presynaptic terminal (Fig. 7) and may include increase in the $\mathrm{Ca}^{2+}$ sensitivity of transmitter release mechanisms downstream of $\mathrm{Ca}^{2+}$ influx. We have not particularly investigated development of the postsynaptic apparatus. However, the postsynaptic non-NMDA receptors seem to be already in the mature form at the period we investigated (P4-P13), at least qualitatively, because both $q$ and the time course of mEPSC decay were not changed significantly in these periods (Fig. 8).

Maturation of synaptic transmission was completed on P8-P9 (Figs. 2C, 5). This conclusion is similar to the observation made at synapses between MNTB and LSO by Kandler and Friauf (1995). They reported that the contralateral synaptic input to LSO through the MNTB principal neuron depolarized the LSO neuron in the early developmental stage and then turned to hyperpolarize the LSO neuron after P8. These postsynaptic potentials were glycinergic, and this developmental change of reversal potential was proposed to be attributable to a decrease of $\left[\mathrm{Cl}^{-}\right]_{\mathrm{i}}$. Therefore, the synapses in the pathway from the contralateral AVCN, through MNTB to LSO, undergo substantial development and become mature at around P8-P9.

\section{Increase in release probability $p$ with development of the MNTB synapse}

The $\mathrm{CV}$ is a function of both the number of release sites $(N)$ and the release probability $(p)$. From the measurement of the $\mathrm{CV}$ alone, we have no way to determine which of these two parameters increased developmentally. If we assume binomial statistics, the ratio of the EPSC variance to the mean $\left(\sigma^{2} / \mu\right)$ will be the product of mean mEPSC amplitude $(q)$ and the probability $(1-$ $p)$, the probability of not releasing a neurotransmitter when the 
A

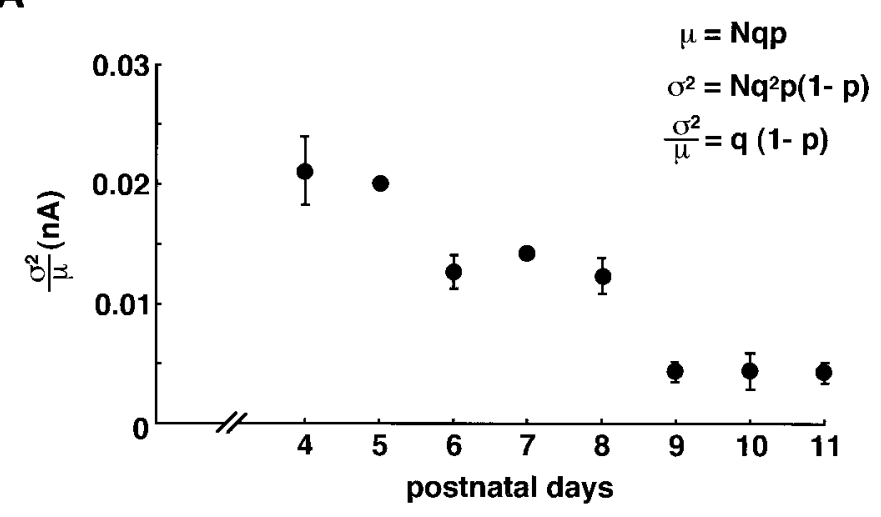

B

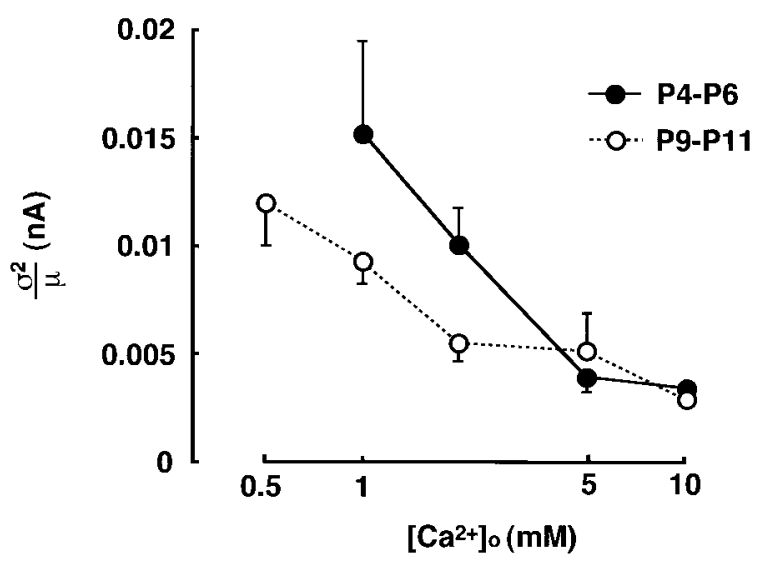

Figure 9. Variance/mean of EPSCs $\left(\sigma^{2} / \mu\right)$ as a function of postnatal day and $\left[\mathrm{Ca}^{2+}\right]_{\mathrm{o}} . A, \sigma^{2} / \mu$ was calculated from the same set of records as Figure 5 and averaged for each postnatal day. Inset, Formulation of $\sigma^{2} / \mu$ in binomial statistics. $B,\left[\mathrm{Ca}^{2+}\right]_{\mathrm{o}}$ dependence of EPSC amplitude fluctuations. $\sigma^{2} / \mu$ was measured from the same set of records shown in Figure 6 for immature $(\bullet, \mathrm{P} 4-\mathrm{P} 6)$ and mature $(\mathrm{O}, \mathrm{P} 9-\mathrm{P} 11) . \sigma^{2} / \mu$ is plotted against $\left[\mathrm{Ca}^{2+}\right]_{\mathrm{o}}$ on semilogarithmic coordinates.

presynaptic fiber is stimulated (see Eq. 2 in Materials and Methods; Fig. $9 A$, inset). $\sigma^{2} / \mu$ has a dimension of current $(A)$. Figure $9 A$ shows the postnatal change of $\sigma^{2} / \mu$. $\sigma^{2} / \mu$ was $0.021 \pm 0.003 \mathrm{nA}$ on P4 (eight cells) and decreased with postnatal development. The decrease saturated after P9 (0.004 $\pm 0.001 \mathrm{nA}, 11$ cells of P9-P11). Because the size of $q$ was constant during this period of postnatal development (Fig. $8 C$ ), this decrease of $\sigma^{2} / \mu$ indicates an increase of $p$.

Using the mean value of $q$, we could calculate $p$ to be 0.34 on P4 and 0.87 on P9-P11. Borst and Sakmann (1996) reported a quantal size of $-43 \mathrm{pA}$ at $-80 \mathrm{mV}$. If we adopted their estimate of $q$ after correcting the difference of holding potential $(-70 \mathrm{mV}$ in our experiments), the estimates of $p$ would become larger at younger ages: 0.49 on P4 and 0.87 on P9-P11.

In calculations of $p$ from $\sigma^{2} / \mu$, we adopted simple binomial statistics assuming a uniform release probability. In cultured hippocampal synapses, terminals of high and low release probabilities were reported in the autapses onto a single hippocampal neuron measured by the different rate of suppression of current through NMDA receptor channels by $(5 R, 10 S)-(+)-5$-methyl10,11-dihydro-5H-dibenzo[a,d]cyclo-hepten-5,10-imine hydrogen maleate (MK801) (Rosenmund et al., 1993) and as the different extent of uptake of fluorescence dye $N$-(3-triethylammonium propyl)-4-(4-(dibutylamino)styryl) pyridinium dibromide in addition to using MK801 (Murthy et al., 1997). We do not have evidence indicating differences in release probabilities between sites of transmitter release within the calyx of Held. Because transmitter release sites in the calyx of Held are in a single terminal structure and probably adjacent to each other, there may not be large differences of release probability among nearby sites.

The number of release sites $N$ was estimated statistically from the $\mathrm{CV}$, and $N$ did not differ significantly among different ages of animals; $N$ varied from 54 to 99 . $N$ was calculated from the mean EPSCs amplitude $(\mu=N p q)$ by adopting the release probability $(p)$ and the size of mEPSC $(q)$ or from the $\mathrm{CV}$ after evaluating $p$; evaluation of $p$ needs estimation of $q$. Therefore, evaluation of $N$ could have greater errors than estimation of $p$ or $q$. Borst and Sakmann (1996) estimated the quantal content $(\mathrm{Np})$ of this synapse in mature animals (P8-P10) and reported 151-210 depending on the method of calculation.

Mature calyces of MNTB synapse have a high probability or a high capability for transmitter release. This feature is appropriate for phase-locked high-fidelity transmission in this auditory relay nucleus. In contrast, in the CA3 $\rightarrow$ CA1 unitary synapse of the hippocampus, release probability was demonstrated to decrease with postnatal development, and at this synapse LTP emerged only when the release probability was reduced either by postnatal development or by reduced $\left[\mathrm{Ca}^{2+}\right]_{\mathrm{o}}$ (Bolshakov and Siegelbaum, 1995). This synapse property would be necessary in mature hippocampus, which appears to be involved in spatial learning (Silva et al., 1992).

\section{Synchronization of the transmitter release}

The morphology of calyx changed drastically during the postnatal days we investigated (Fig. 1). During this postnatal period, the filamentous and radiating filopodia-like processes of presynaptic terminal disappeared, and terminal swellings appeared that ultimately encapsulated the postsynaptic principal neuron of the MNTB. The mature calyx structure would favor phase-locked transmission in the MNTB. Moreover, the phase-locked transmission of this synapse was likely achieved by a synchronized release of neurotransmitters (Fig. 3). Synchronized release should be favored by reduced fluctuation in the time of action potential invasion of the presynaptic terminal after electrical stimulation of the afferent (Fig. 4). This could likely be accomplished by an increase of presynaptic $\mathrm{Na}^{+}$currents and also $\mathrm{K}^{+}$currents. However, the observations made were by whole-cell recording from presynaptic terminals, and the recording itself might have modified the excitability of a small structure such as a presynaptic terminal. Therefore, the reduced fluctuation of action potential invasion time could not be the sole factor to synchronize the EPSC with development. We should not eliminate possibilities of changes of other presynaptic regulatory factors of transmitter release. Particularly, increase of $\mathrm{Ca}^{2+}$ sensitivity of transmitter release would facilitate synchronization (Fig. 6). When release probability $p$ was reduced, Isaacson and Walmsley (1995) observed a large fluctuation in EPSC amplitude and timing of occurrence at the synapses between auditory nerve fibers and AVCN neurons (end bulb of Held); in these experiments $\mathrm{Ca}^{2+}$ influx to the presynaptic terminal was reduced by extracellular application of $\mathrm{Cd}^{2+}(100 \mu \mathrm{M})$.

$\mathrm{Ca}^{2+}$ sensitivity of the $\mathrm{CV}$ became higher with development (Fig. 6), and similar results were obtained when we calculated 
$\sigma^{2} / \mu$ from the same set of records (Fig. 9B). We have not measured the size of mEPSCs at different $\left[\mathrm{Ca}^{2+}\right]_{\mathrm{o}}$. However, because mEPSCs $(-31.2 \pm 2.4 \mathrm{pA})$ induced by $10 \mathrm{~mm} \mathrm{Ba}^{2+}$ were not different from those $(-29.3 \pm 1.6 \mathrm{pA})$ that occurred spontaneously after evoked EPSCs in the standard $2 \mathrm{mM} \mathrm{Ca}^{2+}$ extracellular medium, $q$ was probably not affected by the $0.5-10 \mathrm{~mm}$ $\left[\mathrm{Ca}^{2+}\right]_{0}$ we have used in experiments of Figures 6 and $9 B$ Therefore, the $\mathrm{Ca}^{2+}$ sensitivity of release probability $p$ seems to increase developmentally. This suggests that presynaptic terminals become more efficient in increasing $\left[\mathrm{Ca}^{2+}\right]_{i}$ with development, which in turn increases the $\mathrm{Ca}^{2+}$ sensitivity of the transmitter release mechanisms. The amplitudes of presynaptic $\mathrm{Ca}^{2+}$ currents were increased with development (Fig. 7). In the chick ciliary ganglion, clusters of $\mathrm{Ca}^{2+}$ channels were demonstrated in the membrane facing to the synaptic cleft (Haydon et al., 1994). Greater accumulation of $\mathrm{Ca}^{2+}$ channels in the active zones with development would facilitate release of neurotransmitter.

Asynchronous late release of neurotransmitter was observed in pairs of cultured superior cervical ganglion neurons after injection, into the presynaptic partner, a recombinant $\mathrm{N}$ type $\mathrm{Ca}^{2+}$ channel containing a site interacting with syntaxin and synaptosome-associated protein of $25 \mathrm{kDa}$. The intracellular presence of this fusion protein is expected to disrupt the interaction of $\mathrm{N}$-type $\mathrm{Ca}^{2+}$ channels with syntaxin and to inhibit synaptic transmission (Mochida et al., 1996). $\mathrm{Ca}^{2+}$ sensors with distinct affinity for $\mathrm{Ca}^{2+}$ are reported in hippocampal neurons, and they appear to mediate late release of neurotransmitters when $\mathrm{Sr}^{2+}$ replaced $\mathrm{Ca}^{2+}$ in the extracellular medium (Goda and Stevens, 1994). The increased synchronization of transmitter release with development observed in the present study might indicate addition or replacement of proteins in the synaptic terminal that enhance $\mathrm{Ca}^{2+}$ sensitivity of the neurotransmitter release cascade. The basic mechanisms of membrane fusion and transmitter release triggered by $\mathrm{Ca}^{2+}$ influx appear completed at early phases of development, because the time course of the P4 mEPSC superimposed on the P9 evoked EPSC where neurotransmitter was released with a high degree of synchronization (Fig. $3 C c$ ). This further suggests that the postsynaptic receptors (in particular the non-NMDA glutamate receptors) are already present in the mature form at $\mathrm{P} 4$ in the principal neuron of the MNTB.

\section{REFERENCES}

Aitkin L (1986) Neural coding of sound location. In: The auditory midbrain, pp 145-183. Clifton, NJ: Humana.

Banks IM, Smith PH (1992) Intracellular recordings from neurobiotinlabeled cells in brain slices of the rat medial nucleus of the trapezoid body. J Neurosci 12:2819-2837.

Barnes-Davies M, Forsythe ID (1995) Pre- and postsynaptic glutamate receptors at a giant excitatory synapse in rat auditory brain stem slices. J Physiol (Lond) 488:387-406.

Bolshakov VY, Siegelbaum SA (1995) Regulation of hippocampal transmitter release during development and long-term potentiation. Science 269:1730-1734.

Borst JGG, Sakmann B (1996) Calcium influx and transmitter release in a fast CNS synapse. Nature 383:431-434.

Borst JGG, Helmchen F, Sakmann B (1995) Pre- and postsynaptic whole-cell recordings in the medial nucleus of the trapezoid body of the rat. J Physiol (Lond) 489:825-840. del Castillo J, Katz B (1954) Quantal components of the end-plate potential. J Physiol (Lond) 124:560-573.

Dodge FA, Rahamimoff R (1967) Co-operative action of calcium ions in transmitter release at the neuromuscular junction. J Physiol (Lond) 193:419-432.

Forsythe ID, Barnes-Davies M (1993) The binaural auditory pathway: excitatory amino acid receptors mediate dual timecourse excitatory postsynaptic currents in the rat medial nucleus of the trapezoid body. Proc R Soc Lond [Biol] 251:151-157.

Goda Y, Stevens CF (1994) Two components of transmitter release at a central synapse. Proc Natl Acad Sci USA 91:12942-12946.

Goldberg JM, Brown PB (1968) Functional organization of the dog superior olivary complex: an anatomical and electrophysiological study. J Neurophysiol 31:639-656.

Haydon PG, Henderson E, Stanley EF (1994) Localization of individual calcium channels at the release face of a presynaptic nerve terminal. Neuron 13:1275-1280.

Held H (1893) Die centrale Gehörleitung. Arch Anat Physiol Anat Abteil 201-248.

Isaacson JS, Walmsley B (1995) Counting quanta: direct measurements of transmitter release at a central synapse. Neuron 15:875-884.

Kandler K, Friauf E (1993) Pre- and postnatal development of efferent connections of the cochlear nucleus in the rat. J Comp Neurol 328:161-184.

Kandler K, Friauf E (1995) Development of glycinergic and glutamatergic synaptic transmission in the auditory brainstem of perinatal rats. J Neurosci 15:6890-6904.

Katz B (1966) Nerve, muscle and synapse. New York: McGraw Hill.

Kil J, Kageyama GH, Semple MM, Kitzes LM (1995) Development of ventral cochlear nucleus projections to the superior olivary complex in gerbil. J Comp Neurol 353:317-340.

Korn H, Faber S (1991) Quantal analysis and synaptic efficacy in the CNS. Trends Neurosci 14:439-445.

Koyano K, Ohmori H (1996) Cellular approach to auditory signal transmission. Jpn J Physiol 46:289-310.

Llano I, Marty A, Armstrong CM, Konnerth A (1991) Synaptic- and agonist-induced excitatory currents of Purkinje cells in rat cerebellar slices. J Physiol (Lond) 434:183-213.

Mochida S, Sheng Z-H, Baker C, Kobayashi H, Catterall WA (1996) Inhibition of neurotransmission by peptides containing the synaptic protein interaction site of N-type $\mathrm{Ca}^{2+}$ channels. Neuron 17:781-788.

Morest DK (1968) The collateral system of the medial nucleus of the trapezoid body of the cat, its neuronal architecture and relation to the olivo-cochlear bundle. Brain Res 9:288-311.

Murthy VN, Sejnowski TJ, Stevens CF (1997) Heterogeneous release properties of visualized individual hippocampal synapses. Neuron 18:599-612.

Rosenmund C, Clements JD, Westbrook GL (1993) Nonuniform probability of glutamate release at a hippocampal synapse. Science 262:754-757.

Silva AJ, Paylor R, Wehner JM, Tonegawa S (1992) Impaired spatial learning in $\alpha$-calcium-calmodulin kinase II mutant mice. Science 257:206-211.

Suneja SK, Benson CG, Gross J, Potashner SJ (1995) Evidence for glutamatergic projections from the cochlear nucleus to the superior olive and the ventral nucleus of the lateral lemniscus. J Neurochem 64:161-171.

Takahashi T, Forsythe ID, Tsujimoto T, Barnes-Davies M, Onodera K (1996) Presynaptic calcium current modulation by a metabotropic glutamate receptor. Science 274:594-597.

Wu SH, Kelly JB (1991) Physiological properties of neurons in the mouse superior olive: membrane characteristics and postnatal responses studied in vitro. J Neurophysiol 65:230-246.

Wu SH, Kelly JB (1992) Synaptic pharmacology of the superior olivary complex studied in mouse brain slice. J Neurosci 12:3084-3097. 